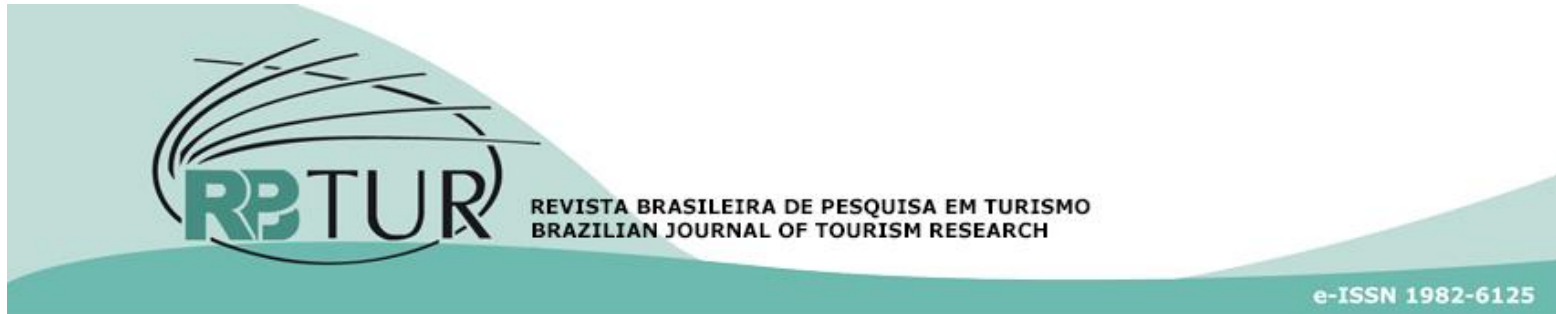

\title{
Artigos
}

\section{O papel de motivações utilitárias e hedônicas na cocriação de valor e sua relação com a experiência no AIRBNB}

\author{
The role of utility and hedonic motivations in value creation and their \\ relationship with AIRBNB experience
}

\section{El papel de la utilidad y las motivaciones hedónicas en la creación de valor y su relación con la experiencia de AIRBNB}

\author{
Gabrielle Maria de Oliveira Chagas ${ }^{1}$; Edvan Cruz Aguiar ${ }^{1}$ \\ 1Universidade Federal de Campina Grande (UFCG), Campina Grande, PB.
}

Palavras-chave:

Consumo Colaborativo.

Motivações.

Cocriação de Valor.

Keywords:

Collaborative Consumption. Motivations.

Value co-creation.
Resumo

O artigo investiga o papel de motivações utilitárias e hedônicas na cocriação de valor e sua relação com a experiência de consumo em serviços de hospedagem oferecido por plataforma de consumo colaborativo: o AirBnb. Baseado na literatura sobre economia compartiIhada e consumo colaborativo, hipóteses foram formuladas e um modelo conceitual proposto. Um survey com 967 respondentes foi conduzido e os dados foram analisados por meio da técnica de modelagem de equações estruturais. Verificou-se que as motivações de cunho utilitário não apresentam relação com cocriação de valor e experiência de consumo, diferentemente das motivações hedônicas que apresentaram associação positiva com ambas variáveis. Ademais, os achados evidenciaram que cocriação de valor, além de anteceder a experiência de consumo, assume papel mediador da relação entre motivações hedônicas e experiência de consumo. Esta pesquisa traz contribuições importantes para a área, uma vez traz evidência empírica do papel que motivações hedônicas exerce em práticas de consumo colaborativo, mais especificamente em serviços de hospedagem compartilhada. Além disso, consubstancia estudos anteriores que reconhecem a cocriação de valor enquanto aspecto importante na oferta de experiência positivas em serviços de hospitalidade e turismo.

\section{Abstract}

The article investigates the role of utilitarian and hedonic motivations in value co-creation and their relationship to consumption experience in a hosting service offered by a collaborative platform: AirBnb. Based on the literature on shared economy and collaborative consumption, hypotheses were formulated and a conceptual model proposed. A survey of 967 respondents was conducted and data analyzed using structural equation modeling technique. Results show that utilitarian motivations are not related to value co-creation and consumption experience, unlike hedonic ones that showed a positive association with both variables. Furthermore, findings show that value co-creation plays role as antecedent of consumption experience as a mediator variable in the relationship between hedonic motivations and consumption experience. This research brings important contributions to the area, since it empirically evidenciates that hedonic motivations are presente in collaborative consumption 
practices, more specifically in shared hosting services. In addition, it consubstanciates previous studies that recognize value co-creation as an important aspect in offering positive experiences in hospitality and tourism services.

\section{Resumen}

\section{Palabras clave:}

Consumo colaborativo.

Motivaciones.

Co-creación de valor.

Revisado por pares.

Recebido em: 19/12/2019.

Aprovado em: 02/04/2020.
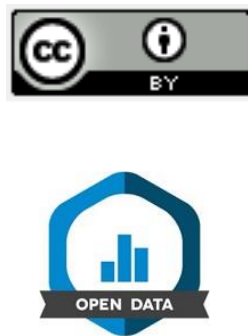

El artículo investiga el papel de las motivaciones utilitarias y hedónicas en la creación conjunta de valor y su relación con la experiencia de consumo en un servicio de alojamiento ofrecido por una plataforma colaborativa: AirBnb. Con base en la literatura sobre economía compartida y consumo colaborativo, se formularon hipótesis y se propuso un modelo conceptual. Se realizó una encuesta a 967 encuestados y se analizaron los datos utilizando la técnica de modelado de ecuaciones estructurales. Los resultados muestran que las motivaciones utilitarias no están relacionadas con la co-creación de valor y la experiencia de consumo, a diferencia de las hedónicas que mostraron una asociación positiva con ambas variables. Además, los resultados muestran que la creación conjunta de valores desempeña un papel como antecedente de la experiencia de consumo como una variable mediadora en la relación entre las motivaciones hedónicas y la experiencia de consumo. Esta investigación aporta importantes contribuciones al área, ya que evidencia empíricamente que las motivaciones hedónicas están presentes en las prácticas de consumo colaborativo, más específicamente en los servicios de alojamiento compartido. Además, constituye estudios previos que reconocen la creación conjunta de valor como un aspecto importante para ofrecer experiencias positivas en servicios de hospitalidad y turismo.

Como citar: Chagas, G. M. O.; Aguiar, E. C. (2020). O papel de motivações utilitárias e hedônicas na cocriação de valor e sua relação com a experiência no AIRBNB. Revista Brasileira de Pesquisa em Turismo, São Paulo, 14 (3), 158-176, set./dez. http://dx.doi.org/10.7784/rbtur.v14i3.1922

Dados abertos: http://dx.doi.org/10.17632/hhtpzvhtkd.1

\section{INTRODUÇÃO}

Ao longo dos últimos anos tem-se observado que um movimento significativo de colaboração está ganhando força nas esferas cultural, política e econômica. A economia compartilhada está ampliando seu espaço na economia a nível global, pois constantemente surgem novas formas de compartilhamento, partindo do pressuposto de que o acesso aos benefícios se torna mais relevante que a posse dos produtos (Denning, 2014; Rifkin, 2014).

Nesse sentido, o ato de consumir deixa de ser representado exclusivamente pela compra e posse de bens e abre espaço para novas possibilidades, como as iniciativas colaborativas, representadas por ações de trocas, empréstimos, aluguéis e outras formas de compartilhamento que permitem aos consumidores o acesso a um bem ou serviço apenas no tempo que julgam necessário (Belk et. al, 2013; Möhlmann, 2015).

Neste contexto surge o conceito de Consumo Colaborativo (CC), compreendido como uma nova configuração de consumo caracterizada por fazer um resgate de antigas práticas de partilha, aluguel e trocas (Algar, 2007; Botsman \& Rogers, 2011). Argumenta-se que o CC pode ser visto como uma possivel solução para promover a reutilização de produtos, a redução de novas compras e o uso de ativos ociosos (Piscicelli et al., 2015).

No consumo colaborativo os indivíduos podem alcançar provedores de serviços diretamente sem a necessidade de intermediários, num misto de conveniência e risco (Ert, Fleischer \& Magen, 2015). Logo, o desenvolvimento desse modelo de consumo está ligado diretamente à internet, uma vez que esta facilita o contato e a interação de pessoas, empresas e de grupos de interesse agregado às facilidades para comprar e compartilhar produtos (Sastre \& Ikeda, 2012).

A literatura acadêmica referente ao CC é vasta quando se analisa as consequências desta prática (Ozanne \& Ballantine, 2010; Bardhi \& Eckhardt, 2012; Lutz \& Newlands, 2018). Entretanto, ainda poucos os trabalhos empíricos que objetivem analisar seus antecedentes, mais especificamente as motivações para o uso de serviços compartilhados. Algumas pesquisas têm evidenciado modelos que demonstram apenas motivações utilitárias enquanto determinantes da adoção de práticas associadas ao consumo colaborativo (Belk, 2010; Bardhi \& Eckardt, 2012; Lamberton \& Rose, 2012).

Contudo, o argumento aqui defendido é de que motivações de cunho hedônico também estão presentes no fenômeno do consumo colaborativo (Benoit, Baker \& Bolton 2017). Ao identificar que uma das motivações 
para participar do consumo colaborativo é realizar atividades junto a pessoas que compartilham dos mesmos interesses, Hamari e Ukkonen (2013) consubstanciam a premissa de que há aspectos não utilitaristas envolvido no CC. Neste mesmo sentido, Stene e Holte (2014) verificaram que fatores sociais e simbólicos se tornam preponderantes, partindo do pressuposto de que entretenimento e auto realização correspondem a motivadores do CC. Porém, muito embora esses autores tenham sugerido presença de motivações hedônicas no CC, ainda nãos e tem suficientes evidências empíricas do seu papel no comportamento de consumo colaborativo.

Além das motivações, Botsman e Rogers (2011) identificam que cada indivíduo que se envolve em práticas de CC cria valor para outras, uma vez que "ao ceder valor para a comunidade, permitimos que o nosso próprio valor social se expanda em troca” (p. 90). Este conceito tem como foco o desenvolvimento do relacionamento entre os stakeholders por meio da interação e do diálogo (Payne, Storbacka \& Frow, 2008).

A cocriação de valor pode ser definida como um processo em que atores seguem por meio de um crescente desenvolvimento de conhecimento e habilidades aplicadas e especializadas, troca de serviço e integração de recursos (Lusch \& Vargo, 2014). Nos serviços, a cocriação ocorre quando clientes realizam atividades que possibilitam a personalização de forma a atender os seus interesses de maneira plena (Ching-Jui et al., 2007; Jayawardhena et al., 2007).

No contexto do CC, Moeller, Ciuchita, Mahr, Odekerken-Schroder e Fassnacht (2013) evidenciaram que a experiência de consumo é a responsável pelos gastos maiores de tempo dos clientes, levando a um aumento de interesse na cocriação de atividades. Paik, Kang e Seamans (2018) verificaram que o crescimento da economia compartilhada influencia o equilíbrio entre interesses privados e públicos para maximizar a criação de valor.

No entanto, ainda não está claro como o valor é criado em redes de compartilhamento. Em outras palavras, existe uma lacuna na literatura de compreender como ocorre a cocriação de valor em redes de consumo colaborativo (Kennedy, 2015; Heo, 2016). Ademais, acredita-se que a proposição de um modelo teórico que se propõe a explicar as motivações para o consumo colaborativo associadas à cocriação pode contribuir para um melhor entendimento do fenômeno, nos mais variados contextos.

Em face disto, percebe-se que atividades no campo do turismo estão alinhadas a práticas de compartilhamento e de consumo colaborativo, sobretudo serviços de hospedagem (ex.: AirBnb, CouchSurfing, TripAdivisor e BeLocal Exchange). O Airbnb, especificamente, é uma plataforma online na qual espaços desocupados (em parte ou em sua totalidade) são anunciados para viajantes do mundo inteiro que buscam hospedagem. A interação virtual acontece mediante perfis sociais e troca de informações em que os interessados podem verificar preferências de acordo com seus interesses (Botsman \& Rogers, 2011), aqui compreendidas como suas motivações.

No contexto brasileiro os serviços oferecidos por esta plataforma têm se destacado. Em 2018 foram mais de 3,8 milhões de imóveis alugados, representando um crescimento de $71 \%$ comparado com o ano anterior (Airbnb, 2019). Segundo dados da Fundação Instituto de Pesquisas Econômicas, os usuários de serviços oferecidos pela plataforma (turista), em comparação com aqueles que utilizam serviços de hospedagem tradicional, geram impacto econômico cerca de R $\$ 2$ bilhões maior (FIPE, 2017, p. 10). Diante do exposto, considerando a pertinência teórica e implicações para praticantes, o presente trabalho se propôs a investigar o papel de motivações utilitárias e hedônicas na cocriação de valor e sua relação com a experiência de consumo em serviços de hospedagem oferecido por plataforma de consumo colaborativo: o AirBnb.

\section{FUNDAMENTOS TEÓRICOS}

\subsection{Consumo colaborativo}

O conceito de CC descrito pela primeira vez por Algar (2007), e posteriormente ampliado por Botsman e Rogers (2011), descreve um comportamento de prática já empregada pela humanidade desde as primeiras formas comerciais (partilha, empréstimos comerciais, aluguel e trocas) transposta para a realidade do século XXI (Algar, 2007). 
Hamari, Sjöklint e Ukkonen (2015) trazem duas definições para sintetizar o entendimento sobre CC: (1) atividade baseada em peer-to-peer para obtenção, doação ou compartilhamento de acesso a bens e serviços, coordenada por serviços online baseados em comunidades; (2) modelo econômico baseado no compartilhamento, troca, escambo, comércio ou aluguel de produtos ou serviços dentro de uma comunidade, em oposição à posse.

Segundo Barnes e Mattson (2017), o CC é a utilização de plataformas, mercados online e redes sociais para promover o compartilhamento de recursos (ex.: dinheiro, bens, habilidades e serviços) entre os pares. Assim sendo, várias são as iniciativas/empresas que se configuram como consumo colaborativo, ao disponibilizar os seus serviços, como por exemplo: eBay, ZipCar, Uber, Airbnb e Freecycle.

Empiricamente, Bardhi e Eckhardt (2012) examinaram o contexto do compartilhamento de carros junto a consumidores da Zipcar, e os achados mostram que os comportamentos de consumo baseados em contextos de compartilhamento se dividem dois tipos de interesses econômicos, da empresa e dos usuários dos serviços. Estes pesquisadores também verificaram que o contexto sociocultural contribui o uso de serviços compartilhados.

Lutz e Newlands (2018) investigaram a segmentação do consumidor na plataforma do Airbnb e constaram que, dentro de uma única plataforma, existe uma ampla variedade de ofertas conforme perfil, características e interesses dos consumidores. Ao reconhecerem o consumo colaborativo enquanto um modelo de negócio competitivo, Coelho e Romero (2019) argumentam que pouco ainda se conhece sobre seus antecedentes. Estes mesmos pesquisadores afirmam que entretenimento e percepção de utilidade são motivadores relevantes para compreender as intenções de uso de serviços compartilhados.

Entende-se que o CC carrega consigo características do consumo tradicional (assinalado pelas trocas de mercado) e de compartilhamento (altruísmo e propriedade compartilhada), correspondendo à uma adaptação da cultura participativa a um modelo de negócios. Portanto, o empresário pode lucrar com o aspecto monetário e estar incluso numa tendência de mercado pró-social e pró-ambiental (Ert, Fleischer \& Magen, 2015), bem como o usuário usufruir dos serviços tendo mais acesso a eles.

Argumenta-se que o CC ainda se encontra ainda em processo de maturação teórica, trazendo à tona à necessidade de mais pesquisas que visem compreender seus motivadores e inibidores enquanto. Para Ozanne e Ballantine (2010), o CC é visto como um tema em ascensão que ainda precisa ser melhor explorado pela literatura, uma vez que somente a partir de 2012 foi identificado um contínuo e crescente número de publicações sobre o consumo colaborativo e a economia compartilhada. Coelho e Romero (2019) consubstanciam o argumento ao afirmarem que não há muito conhecimento acerca das razões que contribuem e inibem as pessoas a participar dessa modalidade de consumo.

\subsection{Motivações do consumo colaborativo}

A motivação para a compra tem sido operacionalizada como um construto bidimensional, que pode ter componente hedônico (natureza subjetiva) e utilitário (natureza funcional), sendo considerada na literatura antecedente das intenções e comportamentos de compra (Batra \& Athola, 1990; Babin et. al., 1994; Dhar \& Wertenbroch, 2000; Voss et. al., 2003).

Em se tratando das motivações para adoção de práticas associadas ao contexto do consumo colaborativo, alguns autores argumentam que atributos racionais e econômicos possibilitam a maximização do uso do bem e a economia de custos (Belk, 2007; Bardhi \& Eckardt, 2012; Lamberton \& Rose, 2012). Em outras palavras, indivíduos engajam-se nessa modalidade de consumo por ela permitir acesso a custos mais baixos. Fremstad (2014) consubstancia este argumento ao afirmar que compartilhar pode trazer benefícios econômicos de forma significativa, uma vez que até os custos de compartilhamento superam os custos agregados. Em estudos mais recentes, analisando mais de três práticas colaborativas, Coelho e Romero (2019) constataram que os benefícios econômicos e a utilidade são os determinantes-chave para os consumidores.

Barnes e Mattsson (2016) verificaram em seus estudos que os maiores direcionadores para o CC são os econômicos, em função dos cenários de crise e a necessidade de se poupar. Em seguida direcionadores tecnológicos apoiados em dispositivos móveis, mídias sociais e internet. E finalmente, direcionadores 
socioculturais, e, com representatividade menor, fatores ambientais. Eles ainda evidenciaram que os principais motivadores para compartilhar são a utilidade e o prazer.

0 argumento aqui defendido é de que para além das motivações de cunho utilitário, motivações hedônicas também assumem papel importante nas práticas de CC. Para Hamari e Ukkonen (2016), de forma genérica, costuma-se atribuir às motivações para participar do consumo colaborativo fatores como diversão e autorealização. Além disso, os consumidores se sentem parte da comunidade, o que contribui para o aumento da sensação de prazer quando da experiência de consumo (Barnes \& Mattson, 2017).

Glind (2013) constatou que os principais motivos que levam os usuários a utilizarem plataformas de CC eram voltados às necessidades práticas, como os ganhos financeiros, de tempo e de reconhecimento, como também tinham caráter social, como conhecer ou ajudar pessoas. Em seu estudo, Stene e Holte (2014) identificaram fatores motivacionais como identidade social, identificação entre os pares e vínculos sociais. Estes fatores se alinham à dimensão hedônica do construto motivação. Möhlmann (2015) obteve como resultado da sua pesquisa que a satisfação e a probabilidade de escolher plataformas de consumo colaborativo podem ser esclarecidas por determinantes que condizem com benefícios pessoais, por exemplo, familiaridade entre os pares e prazer. Neste mesmo sentido, Hamari, Sjöklint e Ukkonen (2016) sugerem que diversão, reputação e auto realização correspondem a aspectos associados à motivação para o consumo colaborativo.

De modo geral, o ato de consumir está associado a uma atividade motivada e direcionada pela crença de que o produto adquirido irá satisfazer as necessidades de quem o consome. Para Pine e Gilmore (1999), o conceito de economia da experiência reside na criação de experiências e emoções que o consumo de determinado produto pode trazer, produzindo oportunidades de vivências individualizadas e, desta forma, singulares.

Pullman e Gross (2003) observam que as experiências de consumo podem ocorrem em contextos físicos (ambiente), relacionais (interações) e temporais (um determinado período de tempo).

No turismo, a experiência de consumo representa uma nova modalidade de tramitação entre as mudanças de mercado, o crescimento tecnológico e a satisfação das necessidades dos clientes (Bujisic, 2014). Apreende-se que a experiência geral do consumidor é tudo que ele vivencia antes, durante e depois de um processo de consumo e, portanto, essa experiência do consumidor modela as reações subjetivas e emocionais dos objetos de consumo e enfatiza os estados emocionais que surgem durante este evento (Wang, Luo \& Tai, 2017).

Holbrook e Gardner (2000) e Mowen e Minor (1998) entendem que as motivações para uma experiência no consumo podem ser de natureza utilitária ou hedônica. Nesse sentindo, é razoável assumir que:

H1: A motivação utilitária tem relação positiva com a experiência de consumo colaborativo.

H2: A motivação hedônica tem relação positiva com a experiência de consumo colaborativo.

Diante dessa nova modalidade de consumo, na qual os indivíduos são avaliados e determinados pela sua reputação, pela comunidade e pelo modo como compartilham bens e serviços, os consumidores estão cada vez mais conectados e tendo novas percepções de valor relacionadas ao ato de consumir (Pera, Occhiocupo \& Clarke, 2016). A literatura tem atribuído grande atenção a contextos de cocriação mediados por tecnologia, uma vez que as empresas permitem que clientes projetem/configurem sua própria experiência de consumo, seja de bens ou de serviços (Franke \& Schreier, 2010; Thomke \& Von Hippel, 2002).

\subsection{Cocriação de valor no consumo colaborativo}

Diferentemente da perspectiva tradicional de criação de valor, que é centrada na empresa, a cocriação de valor surge na literatura com os trabalhos de Prahalad e Ramaswamy (2000, 2004a, 2004b) e Vargo e Lusch (2004), assumindo queo valor não é simplesmente criado e oferecido pela empresa, mas cocriado por meio da interação desta com os consumidores (Vargo \& Lusch, 2004; Gronroos, 2008).

Diversos autores teorizaram sobre o fenômeno da cocriação e com isso, atualmente, a cocriação pode ser estudada sob diversas abordagens. Neste artigo, foi utilizada a perspectiva da Lógica do Serviço Dominante 
(LSD), introduzida por Vargo e Lusch (2004). Nela entende-se que o consumidor possui papel ativo no processo e é sempre um cocriador de valor (Vargo \& Lusch, 2008).

Assim sendo, a cocriação de valor possui benefícios mútuos, pois nota-se a possibilidade de fortalecimento relacional, ao passo em que gera satisfação para os clientes e sua retenção na perspectiva do provedor do serviço (Ching-Jui et al., 2007). A lógica que subjaz essa perspectiva é a de que quanto maior o envolvimento no processo de produção e entrega do serviço, maior o valor percebido, a satisfação e a lealdade do cliente (Ching-Jui et al., 2007; Jayawardhena et al., 2007).

Segundo Ranjan et al. (2019), no que se refere à cocriação de valor, o engajamento do cliente na produção e suas experiências tornou-se uma prática imprescindível no âmbito dos serviços. Consequentemente, empresas tradicionais estão descobrindo o papel do envolvimento do cliente e do colaborador na cocriação de valor para a obtenção vantagem competitiva.

Moeller, Ciuchita, Mahr, Odekerken-Schroder e Fassnacht (2013) evidenciaram que a experiência é a responsável pelos gastos maiores de tempo dos clientes. Ela leva a um aumento de interesse na cocriação de valor durante atividades inerentes ao consumo. Já Paik, Kang e Seamans (2018) verificaram que o crescimento da economia compartilhada influencia o equilíbrio entre interesses privados e públicos para maximizar a cocriação de valor. Dantas et. al (2020) analisaram o processo de cocriação de valor em estabelecimentos hoteleiros por meio do site TripAdivisor, e os achados mostraram que o atendimento de suas expectativas, enquanto resultado da cocriação de valor, é fator relevante. Logo, considerar as motivações dos clientes se mostra necessário, tanto para favorecer a cocriação de valor como para proporcionar uma experiência de consumo agradável ao cliente.

Em sua pesquisa, Verleye (2015) forneceu informações sobre a experiência do cliente em situações de cocriação. Especificamente, o estudo mostra que a experiência de cocriação é um fenômeno multidimensional, sugerindo uma relação com o próprio processo, o ambiente (ex.: tecnologia e conectividade) e interações entre os atores envolvidos. A importância desses fatores, entretanto, difere de acordo com as expectativas dos benefícios da cocriação.

É importante mencionar que a experiência é impulsionada por vicências de cunho pragmático e econômico, o que corresponde à dimensão utilitária da motivação. Hoyer et al. (2010) corroboram este argumento na medida em que ressaltam a importância dos benefícios pragmáticos na forma de melhor atender às necessidades pessoais e os benefícios econômicos na forma de recompensas monetárias. Diante do exposto, foi formulada a seguinte hipótese:

H3: As motivações utilitárias se associam positivamente com a cocriação de valor em práticas de consumo colaborativo.

Sobre os antecedentes da cocriação de valor, a literatura confirma que os clientes esperam benefícios diferentes. Nambisan e Baron (2009) argumentam que quem cocria valor em ambientes virtuais espera benefícios hedônicos (experiências prazerosas) e benefícios sociais (laços relacionais entre os participantes). A partir de uma revisão de literatura, Füller (2010) evidencia que os clientes esperam, em primeiro lugar, tarefas lúdicas intrínsecas, oportunidades para se conectar com pessoas afins, auto-eficácia e reconhecimento enquanto motivadores. Desse modo, é valido assumir que:

H4: As motivações hedônicas se associam positivamente com a cocriação de valor em práticas de consumo colaborativo.

A literatura sugere ainda que a cocriação de valor está associada às respostas do consumidor (atitudinais e comportamentais), como por exemplo: satisfação, recomendação e experiência de consumo. Segundo Gupta e Vajic (2000), a experiência ocorre quando o consumidor tem qualquer tipo de sensação ou conhecimento adquirido como resultado do nível de interação com diferentes elementos de um determinado contexto ou situação. Para Limberger e Mendes (2015), a experiência no turismo pode ser definida como um estado espirito sentido pelos indivíduos e está relacionada com a busca por uma experiência única, distinta da rotina diária, uma busca pela autenticidade. Isso significa dizer que a forma como os consumidores criam valor vai direcionar sua experiência de consumo. A partir disso, foi elaborada a seguinte hipótese de pesquisa: 
H5: A cocriação de valor se relaciona positivamente com a experiência de consumo colaborativo.

Objetivando proporcionar uma melhor compreensão acerca do argumento teórico apresentado e discutido ao longo do presente capítulo, sobretudo as relações propostas, foi elaborado um modelo conceitual (Figura 1).

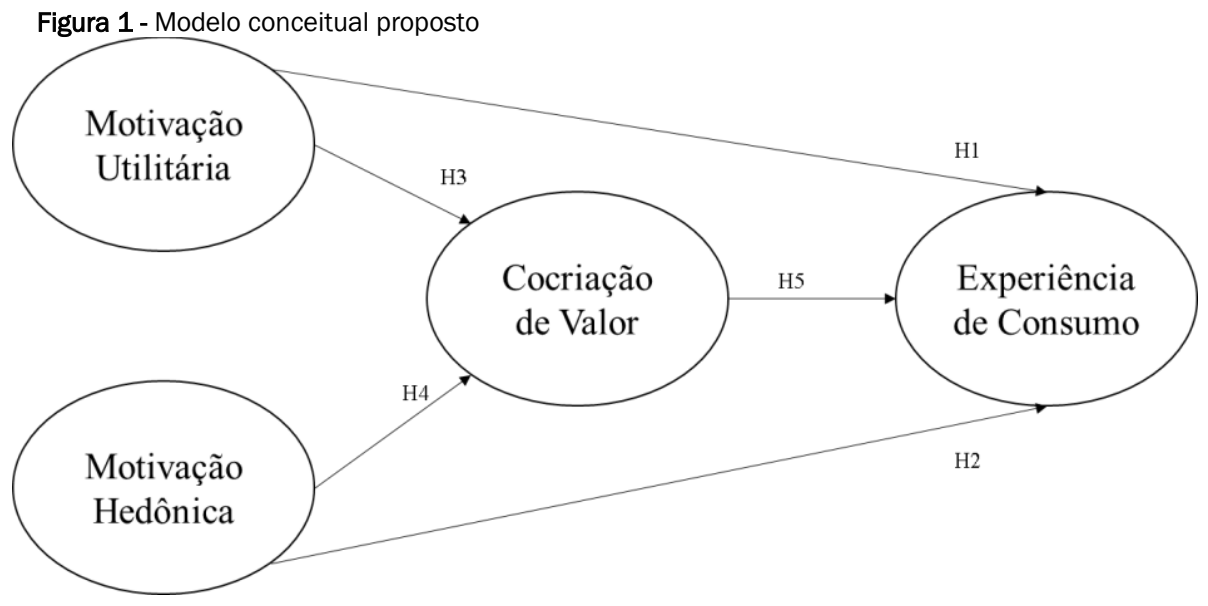

Fonte: Elaborada pelos autores (2020).

\section{PROCEDIMENTOS METODOLÓGICOS}

O presente artigo corresponde a uma pesquisa correlacional de corte transversal, em que o método adotado foi o survey (Babbie, 2003; Martins \& Theóphilo, 2009). Os dados foram coletados por meio de questionário online disponibilizado em grupos voltados para o público em geral que tenha utilizado ao menos uma vez a plataforma Airbnb como hóspede.

\subsection{Instrumento de coleta de dados}

O instrumento de coleta de dados contemplou escalas do tipo Likert de 7 pontos, variando de (1) discordo totalmente a (7) concordo totalmente, para os indicadores de cada construto, a saber: motivação hedônica, motivação utilitária, cocriação de valor e experiência de consumo. Ao todo 13 itens compuseram o questionário, conforme observado no Quadro 1 (definição operacional dos construtos, fonte e seus respectivos indicadores). É importante mencionar que antes da coleta houve a adaptação das escalas (tradução reversa) seguida do pré-teste.

Inicialmente as escalas utilizadas para a mensuração dos construtos foram adaptadas ao contexto da pesquisa. Posteriormente foi conduzido o pré-teste do instrumento, a fim de tornar o questionário mais compreensível do ponto de vista do respondente. Neste estudo piloto, foram obtidos 12 respondentes condizentes com o público da amostra principal. Ato contínuo, poucas mudanças foram realizadas e a versão final do questionário formatada.

Além destes itens, o questionário contou com perguntas de cunho demográfico para fins de caracterização da amostra (sexo, idade, renda mensal individual e escolaridade). 0 instrumento de coleta ainda trouxe questões relacionadas à frequência de utilização da plataforma e o motivo de utilização dos serviços de hospedagem (pessoal ou profissional). 
Quadro 1 - Indicadores dos construtos

\begin{tabular}{|c|c|}
\hline Construto & Indicadores \\
\hline $\begin{array}{l}\text { Motivação Utilitária (Völckner, 2008): baseada } \\
\text { nos atributos funcionais (racionais) dos produ- } \\
\text { tos/serviços. }\end{array}$ & $\begin{array}{l}\text { MU1: Aproveitar o preço reduzido. } \\
\text { MU2: Encontrar um preço mais baixo. } \\
\text { MU3: Não ter que gastar mais dinheiro do que esperado pelo serviço. }\end{array}$ \\
\hline $\begin{array}{l}\text { Motivação Hedônica (Westbrook \& Black, } \\
\text { 1985): baseada nas gratificações afetivas que } \\
\text { os produtos/serviços proporcionam. }\end{array}$ & $\begin{array}{l}\text { MH1: Utilizar os serviços junto com outras pessoas que têm as mesmas prefe- } \\
\text { rências que eu. } \\
\text { MH2: Conversar com outras pessoas interessadas nas mesmas coisas que eu. } \\
\text { MH3: Utilizar os serviços com amigos em ocasião social. }\end{array}$ \\
\hline $\begin{array}{l}\text { Cocriação de Valor (Blasco-Arcas; Hernandez- } \\
\text { Ortega \& Jimenez-Martinez, 2013): valor cocri- } \\
\text { ado por meio da interação entre os consumido- } \\
\text { res e a empresa. }\end{array}$ & $\begin{array}{l}\text { CV1: Senti que participei do processo de criação da minha própria experiência } \\
\text { quando utilizei a plataforma AirBnb. } \\
\text { CV2: Durante minha hospedagem, senti que criei a minha própria experiência. } \\
\text { CV3:A plataforma AirBnb me deu autonomia para ter a experiência que eu que- } \\
\text { ria }\end{array}$ \\
\hline $\begin{array}{l}\text { Experiência de Consumo: } \\
\text { (Holbrook \& Hirschman, 1982; Farias, 2010; } \\
\text { Addis \& Holbrook, 2001): interpretações pesso- } \\
\text { ais de uma situação com base em um histórico } \\
\text { cultural, experiências anteriores, humor e tra- } \\
\text { ços de personalidade. }\end{array}$ & $\begin{array}{l}\text { EdC1: Utilizar a plataforma AirBnb foi uma experiência satisfatória. } \\
\text { EdC2: Utilizar a plataforma AirBnb foi uma experiência positiva. } \\
\text { EdC3: Utilizar a plataforma AirBnb foi uma experiência compensatória. } \\
\text { EdC4: Utilizar a plataforma AirBnb foi uma experiência excelente. }\end{array}$ \\
\hline
\end{tabular}

Fonte: Elaborado pelos autores (2020)

\subsection{Coleta de Dados}

A amostra compreendeu o público em geral que tenha utilizado ao menos uma vez a plataforma Airbnb como hóspede até três meses antes do momento do preenchimento do questionário. Quanto à sua classificação, ela se caracteriza como não probabilística e por acessibilidade. Os dados foram coletados por meio de formulário disponibilizado em grupos de redes sociais de grande abrangência.

Para definir o seu tamanho, fez-se uso das normas práticas recomendadas por Hair et al. (2015), que sugerem um nível desejado de 15-20 observações por parâmetros para Modelagem de Equações Estruturais (MEE). A amostra inicial foi de 967 respondentes com seis construtos de 13 itens psicométricos, sendo considerada apta $(967>13 * 20=260)$ e com um valor muito superior ao recomendado.

\subsection{Análise dos dados}

Inicialmente foi realizada uma inspeção da matriz de dados (data screening). 0 objetivo foi verificar inconsistências de respostas. Ao final deste processo obteve-se um total de 967 observações válidas. 0 passo seguinte foi a verificação da confiabilidade e da validade das escalas utilizadas no estudo. Para tanto, foram analisados os seguintes indicadores: Alpha de Conbrach, Confiabilidade Composta, Variância Média Extraída, Validade Convergente e Validade Discriminante (Hair et al., 2015; Aaker, Kumar \& Day, 2001; Fornell \& Larcker, 1981; Cronbach, 1951).

Para a análise dos dados, o estudo utilizou a técnica de modelagem de equações estruturais baseada em covariâncias (Field, Miles \& Field, 2012; Ribas \& Vieira, 2011). Conforme Anderson e Gerbing (1988), este procedimento estatístico se realiza em duas etapas. Primeiro desenvolve o modelo de mensuração para avaliar a adequação do modelo medido, e por fim se avalia o modelo estrutural, com o propósito de verificar as relações propostas entre as variáveis investigadas. Para auxiliar nos procedimentos de análise, foi utilizado o software estatístico R, Version 3.5.2 para Windows.

\section{RESULTADOS E DISCUSSÃO}

\subsection{Caracterização da amostra}

Este tópico apresenta a descrição do perfil dos sujeitos da pesquisa, que corresponderam a indivíduos que já utilizaram a plataforma AirBnb como hóspedes pelo menos uma vez. A caracterização foi realizada quanto ao gênero, à idade, à renda individual mensal e ao nível de escolaridade. No que diz respeito ao gênero, verificou-se que $60,70 \%$ são mulheres, $37,95 \%$ homens e $1,35 \%$ preferiu não informar. Identificou-se ainda que os respondentes têm uma idade média 35 anos, com uma mediana de 34 e desvio-padrão de 9.7 anos.

Em relação ao nível de escolaridade dos respondentes, notou-se que a maioria das pessoas afirmou ter pósgraduação incompleta $(28,3 \%), 22,1 \%$ tinham nível superior incompleto, $21,8 \%$ ensino superior completo e 
pós-graduação completa e $6 \%$ ensino médio completo. A renda familiar individual obteve uma média de $\mathrm{R} \$ 4.258,00$ com mediana de $\mathrm{R} \$ 3.700,00$.

O nível alto de renda familiar mensal pode ter relação com o nível de escolaridade alto dos respondentes. Além isso, o fato de as pessoas terem condições de viajar, mesmo se tratando de uma hospedagem com um valor reduzido como é o caso do AirBnb, indica que pode se tratar de um público com maior renda. Conforme Pereira (2015), o ato de viajar, embora cada vez mais acessível entre as diversas classes, não é uma prioridade entre as pessoas de menor renda.

As questões buscaram ainda analisar o perfil de uso dos serviços de AirBnb considerando o motivo de uso do serviço (pessoal ou profissional) e a frequência de uso. No que se refere à frequência de uso, os respondentes utilizaram o Airbnb em média 6,7 vezes, com mediana de 6 e desvio-padrão de 3,8. Ao comparar essa variável com gênero, identifica-se que os homens fizeram uso do serviço mais do que as mulheres (médias: 6,87 e 6,55 respectivamente).

O motivo foi investigado pela questão: "Indique por qual motivo você utilizou a plataforma AirBnb". Verificouse que dos 967 respondentes, $77,15 \%$ utilizaram a plataforma por motivos pessoais, como lazer, enquanto que $22,85 \%$ utilizaram por motivos de cunho profissional.

\subsection{Confiabilidade e validade das escalas}

Como o presente estudo adequou escalas específicas para o contexto do consumo colaborativo, adotou-se o procedimento de dois estágios para realizar a análise da modelagem de equações estruturais, conforme sugerido por Anderson e Gerbing (1988). A primeira correspondeu à qualidade e adequação das escalas utilizadas para mensurar as variáveis do estudo, por meio da Análise Fatorial Confirmatória (AFC), verificando assim: confiabilidade, validades discriminante e convergente e, o segundo estágio corresponde a análise da MEE.

No primeiro estágio, a AFC foi testada para identificar se a estrutura fatorial teórica se adequa aos dados observados. De maneira adicional, a análise fatorial confirmatória permitiu testar o ajuste relativo a modelos fatoriais concorrentes (Bagozzi \& Yi, 1988). Desse modo, foram conferidas a confiabilidade das escalas (simples e composta) e a variância média extraída (Tabela 1).

\begin{tabular}{lcccc} 
Tabela 1 - Alpha de Cronbach, Confiabilidade composta e Variância média extraída & & CC & AVE \\
\hline Construto & $N^{\circ}$ de itens & Alpha & 0.960 & 0.909 \\
\hline Motivação Utilitária - MU & 3 & 0.910 & 0.904 & 0.761 \\
Motivação Hedônica - MH & 3 & 0.890 & 0.912 & 0.776 \\
Cocriação de Valor - CV & 3 & 0.910 & 0.918 & 0.675 \\
Experiência de Consumo - EC & 4 & 0.920 & \\
\hline
\end{tabular}

Fonte: Elaborada pelos autores (2020).

Para medir a consistência interna entre os itens, utilizou-se Alpha de Conbrach, essa medida varia entre 0 e 1, sendo que acima de 0,70 considera-se a confiabilidade da escala (Hair et al., 2005). Assim, por meio da Tabela 1, é possível verificar que as escalas mostram confiabilidade adequada, pois os valores foram acima de 0,70 em todos os construtos.

Além disso, a validade dos construtos foi alcançada por meio do estabelecimento da validade convergente e da validade discriminante (Hair et al., 2015). A validade convergente foi acessada tanto com todos os valores da confiabilidade composta (CC) acima do nível mínimo recomendado de 0.6 (Bagozzi \& Yi, 1988), como também com os valores da variância média extraída (AVE) que corresponde a uma medida indicativa de confiabilidade do modelo dos construtos. O valor mínimo considerado para a AVE é igual ou superior a 0.5 (Ruvio \& Shogam, 2008; Fornell \& Larcker, 1981). Todas as variáveis latentes obtiveram o mínimo aceitável, de modo que a validade convergente foi atendida.

Para estabelecer a validade discriminante foi utilizada a metodologia de Chin, Gopal e Salisbury (1997). Ela objetiva verificar em que medida as escalas medem o que se propõem medir, ou seja, espera-se que nessa análise os construtos não se correlacionem fortemente entre si. 
Tabela 2 - Validade discriminante da mensuração do modelo

\begin{tabular}{lcccc} 
Tabela 2 - Validade discriminante da mensuração do modelo & & & \\
\hline Variáveis & Motivação Hedônica & Motivação Utilitária & Cocriação de Valor & Experiência de Consumo \\
\hline Motivação Utilitária & 0.827 & -0.13 & 0.14 & 0.15 \\
Motivação Hedônica & & 0.953 & 0.14 & 0.03 \\
Cocriação de Valor & & & 0.881 & 0.55 \\
Experiência de Consumo & & & 0.821 \\
\hline
\end{tabular}

Fonte: Elaborada pelos autores (2020).

Assim, a raiz quadrada de AVE de cada construto, exposta na diagonal da Tabela 2, foi maior do que o valor do quadrado da correlação entre os outros construtos, garantindo a validade discriminante. Logo, o modelo teórico apresentou confiabilidade e validade adequadas (convergente e discriminante).

\subsection{Estatística descritiva dos construtos}

Com relação à estatística descritiva relacionada aos construtos teóricos utilizados no corrente estudo, a Tabela 3 apresenta duas medidas de tendência central (média e mediana) e uma de dispersão (desvio padrão). Dentre todos os construtos apresentados na Tabela 3, a motivação utilitária foi a que obteve maior média $(5,88)$ e o segundo menor desvio padrão $(1,5)$, indicando pouca variabilidade em torno da média. Verificando uma presença maior do utilitarismo no uso dos serviços do AirBnb, o que é corroborado por Belk (2007) e Lamberton e Rose (2012), quando mencionam em seus estudos que atributos racionais e econômicos possibilitam a maximização do uso e a economia de custos. Ou seja, indivíduos engajam-se nessa modalidade de consumo por ela permitir acesso a custos mais baixos.

Acompanhado da motivação utilitária tem-se o construto experiência de consumo com uma média de 5,77 e o menor desvio padrão $(1,49)$ indicando que os respondentes identificam o uso dos serviços do AirBnb como uma experiência positiva e satisfatória.

Tabela 3 - Estatísticas descritivas dos construtos

\begin{tabular}{lccc}
\hline Construtos & Média & Mediana & Desvio-padrão \\
\hline Motivação Utilitária - MU & 5,88 & 6,33 & 1,5 \\
Motivação Hedônica - MH & 5,66 & 6,77 & 1,72 \\
Cocriação de Valor - CV & 4,63 & 5 & 1,75 \\
Experiência de Consumo - EC & 5,77 & 6 & 1,49 \\
\hline
\end{tabular}

Fonte: Elaborada pelos autores (2020).

A terceira maior média e o terceiro menor desvio padrão se refere a motivação hedônica $(5,66$ e 1,72 respectivamente), o que indica pouca variabilidade em torno da média. E, apesar da média menor em relação à média da motivação utilitária, pode-se inferir a presença do hedonismo no AirBnb. Hamari e Ukkonen (2013), Glind (2013) e Möhlmann (2015) fortalecem o argumento de que para além de motivações utilitárias, as motivações hedônicas também assumem um papel importante como antecedentes às práticas de consumo colaborativo. Por fim, tem-se o construto cocriação de valor com média de 4,63 e desvio-padrão de 1,75 .

\subsection{Análise do modelo de mensuração}

Após verificação da validade convergente e discriminante, foi testado o modelo estrutural (Bagozzi \& Yi, 2012; Anderson \& Gerbing, 1988). O método de máxima verossimilhança, comumente utilizado nos estudos da área do comportamento do consumidor (ex: Jaiswal \& Kant, 2018; Paul et al., 2016; Yadav \& Pathak, 2016), foi utilizado para análise das estimativas e índices de ajustamento do modelo.

A avaliação do goodness-of-fit (GOF) foi feita por múltiplos indicadores: $\chi^{2}$ (qui-quadrado), $X^{2} / G l$ (qui-quadrado por graus de liberdade), NFI (índice de ajuste normalizado), IFI (Índice de Ajuste Corrigido), TLI (índice de Tucker-Lewis, CFI (índice de ajuste comparativo), GFI (goodness-of-fit index), RFI (Índice de Ajuste Relativo), RMSEA (raiz do erro quadrático médio de aproximação) e SRMR (raiz quadrada média residual padronizado). 


\begin{tabular}{lcc}
\multicolumn{2}{l}{ Tabela 4 - Validade discriminante da mensuração do modelo } \\
\hline Índice & Critério & Modelo estrutural \\
\hline$X^{2}$ & - & 423.949 \\
Gl & -- & 62 \\
NFI & $\geq 0,900$ & 0.972 \\
IFI & $\geq 0,900$ & 0.976 \\
TLI & $\geq 0,900$ & 0.970 \\
CFI & $\geq 0,900$ & 0.976 \\
GFI & $\geq 0,900$ & 0.939 \\
RFI & $\geq 0,900$ & 0.965 \\
RMSEA & $\leq 0,08$ & 0.078 \\
SRMR & $\leq 0,05$ & 0.042 \\
\hline
\end{tabular}

Fonte: Elaborada pelos autores (2020).

Conforme pode ser observado na Tabela 4, o modelo obteve qui-quadrado ( $x 2$ ) igual a 432,040 e 62 graus de liberdade (gl). Os índices de ajustamento (NFI, IFI, TLI, CFI, GFI e RFI), que comparam o modelo proposto com o modelo nulo, estão todos perto do critério 1.0 de ajuste perfeito (Kline, 2011). Em relação ao RMSEA, verifica-se que também apresenta ajustamento aceitável, uma vez que valores entre 0,05 e 0,08 são considerados aceitáveis (Arbuckle, 2012). 0 mesmo ocorrendo com o SRMR. Estes resultados indicam um ajuste apropriado na mensuração dos construtos latentes. Portanto, a adaptação das escalas mostrou-se adequada, possibilitando aplicar a segunda etapa da MEE.

\subsection{Teste de estruturação do modelo}

As hipóteses do modelo original proposto foram testadas a partir da avaliação da significância dos parâmetros padronizados (Tabela 5).

\begin{tabular}{lccccc}
\multicolumn{2}{l}{ Tabela $5-$ Teste das hipóteses (modelo estrutural) } \\
\hline Hipótese & $\boldsymbol{\beta}$ & Erro & z-value & p-value & Status \\
\hline H1. $\mathrm{MU} \rightarrow \mathrm{EC}$ & -0.028 & 0.027 & -1.019 & 0.308 & Não suportada \\
H2. $\mathrm{MH} \rightarrow \mathrm{EC}$ & 0.054 & 0.023 & 2.346 & 0.018 & Suportada \\
H3. $\mathrm{MU} \rightarrow \mathrm{CV}$ & 0.044 & 0.040 & 1.105 & 0.269 & Não suportada \\
H4. $\mathrm{MH} \rightarrow \mathrm{CV}$ & 0.144 & 0.033 & 4.330 & 0.000 & Suportada \\
H5. $\mathrm{CV} \rightarrow \mathrm{EC}$ & 0.481 & 0.025 & 19.486 & 0.000 & Suportada \\
\hline
\end{tabular}

Inicialmente verifica-se que a relação entre motivações de cunho utilitário com a experiência de consumo, além de ser negativa, não foi estatisticamente significativa $(\beta=-0.028, p=0.308$ ). Apesar de estudos anteriores evidenciarem que atributos racionais e econômicos possibilitam a maximização do uso do bem e a economia de custos (Belk, 2007; Bardhi \& Eckardt, 2012; Lamberton \& Rose, 2012), este achado não corrobora esta premissa.

MöhImann (2015) obteve como resultado da sua pesquisa que a satisfação e a probabilidade de escolher plataformas de consumo colaborativo podem ser esclarecidas por determinantes que condizem com benefícios pessoais e prazer, o que difere de aspectos de caráter utilitário. Portanto, a hipótese H1 não foi suportada. Neste mesmo sentido, Hamari, Sjöklint e Ukkonen (2016) sugerem que diversão, reputação e auto realização correspondem a aspectos associados à motivação para o consumo colaborativo. Portanto, 0 entendimento é de que no que se refere ao AirBnb, o utilitarismo pode não apresentar efeito direto sobre a experiência de consumo colaborativo.

Neste mesmo sentido, verifica-se ainda que a motivação utilitária não apresenta associação significante com a cocriação de valor $(\beta=0.044, p=0.269)$. Desse modo, não há evidências suficientes para rejeitar a hipótese nula (H3 não suportada). Muito embora a literatura reconheça que a cocriação apresente elementos associados tanto a aspectos hedônicos quanto utilitários (Verleye, 2015), este resultado sugere que o papel das motivações utilitárias pode variar conforme o tipo do serviço e sua proposta de experiência, como no caso de serviços de hospedagem para turistas (Prebensen \& Xie, 2017).

No que diz respeito às motivações de cunho hedônico, verificou-se que elas possuem relação positiva e significativa com cocriação de valor $(\beta=0.144, p<0.001$ ) e experiência de consumo $(\beta=0.054, p=0.018)$, 
o que suporta as hipóteses H2 e H3, respectivamente. Este achado evidencia que, para além de motivações utilitárias, o envolvimento em práticas de consumo colaborativo contempla hedonismo. Neste estudo, com ênfase em serviços de hospedagem (Airbnb), entende-se que esta variável assume papel de antecedente da cocriação de valor e da experiência de consumo.

Desse modo, é importante destacar que a pesquisa traz evidências do papel que motivações hedônicas assume no consumo colaborativo (Hamari, Sjöklint, \& Ukkonen, 2016; Benoit, 2017). Sob a perspectiva do turismo, argumenta-se que para satisfazer consumidores é preciso compreender as exigências de valor dos clientes e então uma oferta de valor única baseada nessas exigências (O'Cass \& Sok, 2015). 0 ponto de vista experiencial do consumo concentra-se nos aspectos não utilitários (Frow \& Payne, 2007), e tendo em conta que se trata de um fenômeno dinâmico, mutável e que emerge de contextos específicos (Kelleher \& Peppard, 2010), tornou-se um elemento-chave na compreensão do comportamento do consumidor.

Reconhecer a pertinência das motivações, especialmente as hedônicas, em práticas de consumo colaborativo permite a gestores, empresas e demais envolvidos nesta modalidade desenvolver políticas e ações que permitam proporcionar agradáveis experiências de consumo considerando a cocriação de valor enquanto um elemento importante. Logo, estes resultados sugerem que as motivações hedônicas contribuem para que o processo de cocriação de valor seja efetivo. Ademais, elas se associam fortemente com a experiência de consumo em serviços de hospedagem nos moldes da proposta da empresa Airbnb.

Parte-se do pressuposto de que quem cocria em ambientes virtuais espera experiências prazerosas e laços relacionais (Nambisan \& Baron, 2009; Füller, 2010). Neste mesmo sentido, as interações de alta qualidade nos serviços permitem ao consumidor cocriar experiências únicas e são a solução para desvendar novas fontes de vantagem competitiva (Prahalad \& Ramaswamy, 2004).

Com relação à hipótese $\mathrm{H} 5$, os dados suportam a premissa de que a cocriação de valor se relaciona positivamente com a experiência de consumo colaborativo $(\beta=0.481, p<0.001)$. Ressalta-se ainda que a cocriação de valor apresenta maior nível de associação com a experiência de consumo $(\beta=0.481)$, comparando-se às motivações utilitárias $(\beta=-0.028)$ e hedônicas $(\beta=0.054)$. Considerando as hipóteses anteriormente avaliadas, percebe-se que a partir do modelo proposto a cocriação de valor assume papel de variável mediadora das motivações hedônicas sobre a experiência de consumo colaborativo em serviços de hospedagem (Airbnb).

Pesquisadores na área do turismo entendem que a cocriação de valor é algo que as organizações devem gerenciar para garantir maior satisfação com o serviço e lealdade à marca (ex.: Grissemann \& StokburgerSauer, 2012; Rihova, Buhalis, Gouthro, \& Moital, 2018). Segundo Busser e Shulga (2018), provedores de serviços em hospitalidade e turismo estão engajando clientes em atividades de cocriação com o objetivo de alcançar resultados positivos reciprocamente, e o presente estudo também evidencia a existência da cocriação de valor no contexto aqui investigado, bem como sua relação antecedente com as motivações hedônicas do cliente e consequente com a experiência de consumo.

É importante que as empresas do setor turístico permitam aos seus clientes cocriar os produtos e serviços, tornando-o mais pessoal e customizado. Os serviços de hospedagem oferecidos por meio da plataforma Airbnb possibilitam aos clientes (turistas) encontrar as opções que mais se alinham às suas demandas, além de acordar algumas questões com o host (quem recebe o turista), o que está alinhado ao conceito de cocriação de valor.

Logo, além de consubstanciar empiricamente a existência de cocriação de valor em práticas de consumo colaborativo (alinhadas às motivações hedônicas), esta investigação ressalta a pertinência destas duas variáveis enquanto determinantes da experiência de consumo em serviços de hospedagem. A Figura 2 apresenta o modelo estrutural, que representa as relações propostas no presente estudo. 
Figura 2 - Modelo estrutural final

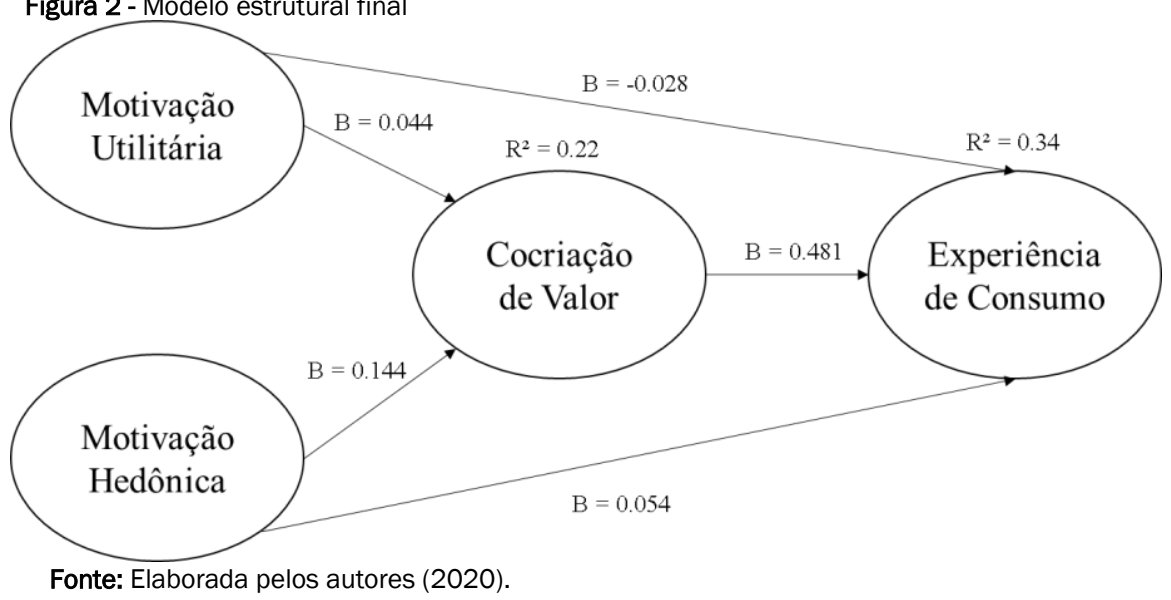

Conforme pode ser observado no modelo, $22 \%$ da variação da cocriação de valor estão associados às motivações ( $R^{2}$ ajustado $=0.22$ ) e que $34 \%$ da experiência de consumo em serviços de hospedagem (Airbnb) são explicados pelas motivações e pela cocriação de valor $\left(R^{2}\right.$ ajustado $\left.=0.34\right)$. Com base nos dados, verifica-se ainda o papel mediador da cocriação de valor na relação entre motivações hedônicas e experiência de consumo.

Argumenta-se que o valor deve ser criado em conjunto pelas organizações e pelos consumidores, residindo na própria experiência de consumo (Minkiewicz et al., 2014). Nesta mesma perspectiva, a experiência dos consumidores sustenta a ênfase na cocriação de valor (Prahalad \& Ramaswamy, 2004; Vargo \& Lusch, 2004, 2008).

Os resultados aqui apresentados vão ao encontro da literatura na área, no que diz respeito à importância das motivações hedônicas para explicar o comportamento do consumidor e as suas decisões de consumo dentro do consumo colaborativo (Hamari \& Ukkonen, 2013; Glind, 2013; Stene \& Holte, 2014; Hamari, Sjöklint, \& Ukkonen, 2016).

Entende-se que o prazer em participar ativamente do processo que envolve a entrega do serviço corresponde a fator determinante de atitudes e intenções de comportamento associados às práticas de consumo colaborativo. Além disso, quando há a identificação de identidade em determinado grupo, os indivíduos participantes sentem-se impelidos de compartilhar entre si (Hamari \& Ukkonen, 2013). A seção seguinte apresenta as conclusões do trabalho.

\section{CONCLUSÕES}

Este estudo investigou o papel de motivações utilitárias e hedônicas na cocriação de valor e sua relação com a experiência de consumo em serviços de hospedagem oferecido por plataforma de consumo colaborativo: o AirBnb. A pesquisa evidenciou que as motivações hedônicas assumem papel de antecedente da experiência de consumo e apresentando relação positiva com a cocriação de valor. Por outro lado, aquelas de cunho utilitário não apresentaram relação.

Também foi possível verificar que a cocriação de valor se relaciona com a experiência de consumo, bem como assume papel de variável mediadora da relação entre experiência de consumo e motivações hedônicas. Os achados desta investigação corroboram as discussões sobre o comportamento do consumidor no CC (Hamari \& Ukkonen, 2013; Stene \& Holte, 2014; Hamari, Sjöklint, \& Ukkonen, 2016; Benoit, Baker, \& Bolton, 2017), mais especificamente seus antecedentes, bem como a literatura na área de turismo que reconhece a pertinência da co-criação de valor (O'Cass \& Sok, 2015; Prebensen \& Xie, 2017 , Grissemann \& Stokburger-Sauer, 2012; Rihova et al., 2018).

0 trabalho reitera o argumento de que é importante que as empresas do setor turístico permitam aos seus clientes cocriar os produtos e serviços, tornando-o mais pessoal e customizado, pois assim pode-se alcançar resultados positivos reciprocamente (clientes e provedores de serviços). Ao além evidenciar a existência de cocriação de valor em práticas de consumo colaborativo (alinhadas às motivações hedônicas), esta 
investigação ressalta a pertinência destas duas variáveis enquanto determinantes da experiência de consumo em serviços de hospedagem.

A contribuição do corrente estudo reside no fato de validar a premissa de que motivações hedônicas também estão presentes em práticas de consumo colaborativo. Muito a embora a literatura enfatize os aspectos utilitários (ex.: economia de recursos), este artigo sugere que há ofertas de serviços alinhadas ao CC em que o hedonismo é mais determinante, sobretudo quando é considerada a experiência de consumo.

Assumindo que há uma concepção maior envolvendo a colaboração e o consumo, não apenas focada em retorno financeiro ou tangível, a sociedade está reaprendendo a criar valor a partir de recursos compartilhados, equilibrando interesses individuais com o bem da comunidade. A troca de experiência com o anfitrião contribui para que os hóspedes tenham outra visão sobre o local, algo mais alinhado ao conceito de cocriação de valor. Hospedagens compartilhadas permitem às pessoas criarem e manterem conexões sociais, oportunizando a geração vínculo com comunidades locais e uma experiência local única.

O estudo do fenômeno consumo colaborativo tem grande relevância para o desenvolvimento econômico e o bem-estar social nos países, tendo em vista que, a longo prazo, esses novos modelos de economia compartilhada tendem a se tornar mainstream, promovendo desenvolvimento sustentável por meio de inovação tecnológica. Logo, no âmbito dos serviços de turismo, entende-se ser pertinente que os profissionais do Turismo estejam preparados para encarar as mudanças oriundas do desenvolvimento tecnológico.

O presente trabalho colabora para as investigações acerca do turismo contemporâneo na perspectiva de um fenômeno que tem despertado aos poucos a atenção da academia, que é o comportamento do turista no contexto do consumo colaborativo. Arnould e Rose (2015) sinalizaram a ideia de que práticas de CC abriram uma nova frente na teoria de circulação de recursos até então negligenciada pela literatura.

Mesmo atendendo seu objetivo e trazendo contribuições para a área, esta pesquisa apresenta limites e limitações. O escopo do trabalho centrou-se apenas em uma empresa (Airbnb). Assim é preciso parcimônia ao extrapolar os achados aqui encontrados para empresas que apresentam modelo de negócio similar. A amostra foi do tipo não probabilística, de modo que perspectivas de generalização para outros contextos ficam comprometidas.

A plataforma utilizada enquanto objeto de estudo (Airbnb) tem três opções: estadias, experiências e aventuras. Este artigo não fez distinção por categoria. Neste mesmo sentido a plataforma tem como clientes principais o host (quem hospeda) e o turista (que faz uso do serviço de hospedagem). 0 trabalho aqui conduzido focou no segundo grupo.

Portanto, como sugestão de pesquisas futuras, recomenda-se realizar estudo com amostra a nível nacional, considerando o tipo de opção. Assim poderia ser aplicada uma modelagem de equações estruturais seguida de multi-group moderation e, mais especificamente, comparar os efeitos de motivações hedônicas e cocriação de valor conforme a opção. Neste mesmo sentido, uma pesquisa com os hosts. Também é válido considerar, a partir do modelo conceitual proposto, estudos que incluam variáveis mediadores como confiança e risco percebido.

\section{AGRADECIMENTOS}

Este trabalho foi realizado com o apoio da FAPESQ (Fundação de Amparo à Pesquisa do Estado da Paraíba).

\section{REFERÊNCIAS}

Aaker, D. A.; Kumar, V.; Day, G. S. (2001). Pesquisa de marketing. São Paulo: Atlas.

Algar, R. (2007) Collaborative consumption. Leisure Report.

Anderson, J. C., \& Gerbing, D. W. (1988). Structural equation modeling in practice: A review and recommended two-step approach. Psychological Bulletin, 103(3), 411-423. https://doi.org/10.1037/00332909.103.3.411 
Anderson, J. C., \& Gerbing, D. W. (1988). Airbnb cresce $71 \%$ em chegadas de hóspedes no Brasil em 2018. 22 de janeiro de 2019. Disponível em: https://news.airbnb.com/br/airbnb-cresce-em-hospedes2018/. Acesso em: 17 mar. 2020. https://doi.org/10.12819/2020.17.4.5

Arbuckle J. L. (2012) IBM SPSS Amos 21. Amos Development Corporation, Chicago, IL.

Arnould, E. J.; Rose, A. S. (2015). Mutuality: Critique and substitute for Belk's “sharing”. Marketing Theory, 1-25. https://doi.org/10.1177/1470593115572669

Babbie, E. (2003). Survey research methods. Belmont, California. Wadsworth Pub. Co: USA.

Babin, B. J.; Darden, W. R. \& Griffin, M. (1994) Work and/or Fun: Measuring hedonic and utilitarian shopping value. Journal of Consumer Research, 20(4) 644-656. https://doi.org/10.1086/209376

Bagozzi, R. P., \& Yi, Y. (1988). On the evaluation of structural equation models. Journal of The Academy of Marketing Science, 16(1), 74-94. https://doi.org/10.1007/BF02723327

Baker, J. Levy, M. \& Grewal, D. (1992) An experimental approach to making retail store environment decisions. Journal of Retailing 68(4), 445-460.

Bardhi, F.; Eckhardt, G. M. (2012). Access-based Consumption: The Case of Car Sharing. Journal of Consumer Research, 39, 81-98. https://doi.org/10.1086/666376

Barnes, S. J. \& Mattsson, J. (2016). Understanding current and future issues in collaborative consumption: A four-stage Delphi study.Technological Forecasting and Social Change, 104, 200-211. https://doi.org/10.1016/j.techfore.2016.01.006

Batra, R. \& Athola, O. (1990) Measuring the hedonic and utilitarian sources of consumer atitudes. Marketing Letters , 2(2), 159-170. https://doi.org/10.1007/BF00436035

Belk, R. (2007). Why not share rather than own? Annals of the American Academy of Political and Social Science, 611,126-140. https://doi.org/10.1177/0002716206298483

Belk, R. (2010). Sharing. Journal of Consumer Research, 36, 715-734. https://doi.org/10.1086/612649

Belk, R.; Fischer, E.; Kozinets, R. V. (2013). Qualitative consumer and marketing research. London: Sage.

Benoit, S.; Baker, T.L.; Bolton, R. N.; Gruber, T.; Kandampully, J. (2017). A triadic framework for collaborative consumption (CC): Motives, activities and resources \& capabilities of actors. Journal of Business Research, 79, 219-227. https://doi.org/10.1016/j.jbusres.2017.05.004

Bitner, M. J. (1990) Evaluating service encounters: The effects of physical surroundings and employee responses. Journal of Marketing 54(2), 69-82. https://doi.org/10.1177/002224299005400206

Blasco-Arcas, L; Hernandez-Ortega, B. e Jimenez-Martinez, J. (2014). The online purchase as a contexto for co-creating experiences: Drivers of and consequences for customer. behavior. Internet Research, 24(3). https://doi.org/10.1108/IntR-02-2013-0023

Botsman, R.; Rogers, R. (2011). o que é meu é seu: Como o consumo colaborativo vai mudar o nosso mundo. Porto Alegre: Bookman. Business Review, 79-87.

Bujisic, M., Hutchinson, J., \& Parsa, H. G. (2014). The effects of restaurant quality attributes on customer behavioral intentions. International Journal of Contemporary Hospitality Management. https://doi.org/10.1108/IJCHM-04-2013-0162

Kelleher, C.; J, Peppard. (2011). Consumer experience of value creation: A phenomenological perspective, in $E$ - European Advances in Consumer Research Volume 9, eds. Alan Bradshaw, Chris Hackley, and Pauline Maclaran, Duluth, MN :Association for Consumer Research, Pages: 325-332.

Chin, W. W., Gopal, A., \& Salisbury, W. D. (1997). Advancing the theory of adaptive structuration: The development of a scale to measure faithfulness of appropriation. Information Systems Research, 8(4), 342-367. https://doi.org/10.1287/isre.8.4.342

Ching-Jui, K., Tseng-Lung, H., Li-Jie, Z.; Hsu, K. (2007). Modeling service encounters consumer attitudes. Marketing Letters 2(2), 159-170.

Coelho, P. F. \& Romero, C. B. (2019). Determinantes de diferentes tipos de consumo colaborativo. Revista de Administração FACES Journal, 18(3).

Cronbach, L. J. (1951). Coefficient alpha and the internal structure of tests. Psychometrika, 16(3), 297334. https://doi.org/10.1007/BF02310555 
Dantas, B. L., Leal, J. S., Peixoto, A. F., Mano, R. F., \& de Abreu, N. R. (2020). A cocriação de valor em estabelecimentos hoteleiros por meio do site TripAdvisor. Revista Brasileira de Administração Científica, 11(1), 161-176. https://doi.org/10.6008/CBPC2179-684X.2020.001.0012

Denning, S. (2014). Metrics for the emerging creative economy. Strategy \& Leadership, Chicago, 42(5), 1827. https://doi.org/10.1108/SL-08-2014-0057

Dhar, R \& Wertenbroch, K. (2000). Consumer Choice Between Hedonic and Utilitarian Goods. Journal of Marketing Research 37(1), 60-71. https://doi.org/10.1509/jmkr.37.1.60.18718

Ert, E.; Fleischer, A.; Magen, N. (2016). Trust and reputation in the sharing economy: The role of personal photos in Airbnb. Tourism Management, 55, 62-73. https://doi.org/10.1016/j.tourman.2016.01.013

Field, A., Miles, J., \& Field, Z. (2012). Discovering statistics using R. Sage publications.

Fitzsimmons, J. \& Fitzsimmons, M., Eds., New service development. Thousand Oaks: Sage, 33-51.

Fodness, D. (1994). Measuring tourist motivation. Annals of Tourism Research, 21(3). https://doi.org/10.1016/0160-7383(94)90120-1

Fornell, C.; Larcker, D. F. (1981). Evaluating structural equation models with unobservable variables and measurement error. Journal of marketing research, 18(1), 39-50. https://doi.org/10.1177/002224378101800104

Franke, N.; Schreier, M. \& Kaiser, U. (2010). Management Science, 56(1), 125-140. https://doi.org/10.1287/mnsc.1090.1077

Fremstad, A. Gains from sharing: Sticky norms, endogenous preferences and the economics of shareable goods (2014). Economics Department Working Paper Series, 168.

Füller, J. (2010) Refining Virtual Co-Creation from a Consumer Perspective. California Management Review 52(2), 98-122. https://doi.org/10.1525/cmr.2010.52.2.98

Grissemann, U. S., \& Stokburger-Sauer, N. E. (2012). Customer co-creation of travel services: The role of company support and customer satisfaction with the cocreation performance. Tourism Management, 33(6), 1483-1492. https://doi.org/10.1016/j.tourman.2012.02.002

Gronroos, C. (2008) Service logic revisited: Who creates value? And who co-creates? European Business Review, 20, 298-314. https://doi.org/10.1108/09555340810886585

Gupta, S. \& Vajic, M. (2000) The Contextual and Dialectical Nature of Experiences. In: Fitzsimmons, J. and Fitzsimmons, M., Eds., New Service DevelopmentThousand Oaks: Sage 33-51. https://doi.org/10.4135/9781452205564.n2

Hair, J.F.; Black, W.C.; Babin, B.J.; Anderson, R.E. \& Tatham, R.L. (2015). Multivariate data analysis (7th Edition).

Hamari, J \& Ukkonen, A. The Sharing Economy: Why People Participate in Collaborative Consumption. Social Science Research Network, Helsinki, March, 2013. Disponível em: http://papers.ssrn.com/sol3/papers.cfm?abstract id=2271971. Acesso em: 19 out. 2019. https://doi.org/10.2139/ssrn.2271971

Hamari, J.; Sjöklint, M. \& Ukkonen, A. (2016). The sharing economy: Why people participate in collaborative consumption. Journal of the Association for Information Science and Technology, 67(9), 2047-2059. https://doi.org/10.1002/asi.23552

Heo, C. Y. (2016). Sharing economy and prospects in tourism research. Annals of Tourism Research. https://doi.org/10.1016/j.annals.2016.02.002

Holbrook, M. B \& Gardner, M. P. (2000) Illustrating a Dynamic Model of the Mood-Updating Process in Consumer Behavior. Psychology \& Marketing. 17(3), 165-194. https://doi.org/10.1002/(SICI)15206793(200003)17:3<165::AID-MAR1>3.0.C0;2-5

Hoyer, W. D.; Chandy R.; Dorotic, M. \& Krafft, M. (2010) Consumer cocreation in new product Development. Journal of Service Research 13(3). https://doi.org/10.1177/1094670510375604

Jaiswal, D., \& Kant, R. (2018). Green purchasing behaviour: A conceptual framework and empirical investigation of Indian consumers. Journal of Retailing and Consumer Services, 41, 60-69.

https://doi.org/10.1016/j.jretconser.2017.11.008 
Jayawardhena, C., Souchon, A.L., Farrell, M. \& Glanville, K. (2007). Outcomes of service encounter quality in business-to-business contexto. Industrial Marketing Management 36(5):575-588. https://doi.org/10.1016/j.indmarman.2006.02.012

Kennedy, J. (2015). Conceptual boundaries of sharing. Information, Communication \& Society. https://doi.org/10.1080/1369118X.2015.1046894

Kline, R. B. (2011). Beyond significance testing: Reforming data analysis methods in behavioral research. Washington, DC: American Psychological Association.

Lamberton, C. P. \& Rose, R. (2012). When is ours better than mine? A framework for understanding and altering participation in consumer sharing systems. Journal of Marketing, 76, 109-125. https://doi.org/10.1509/jm.10.0368

Limberger, P. F., \& Mendes, J. (2015). O modelo de gestão da European Foundation For Quality Management (EFQM) para destinos turísticos: uma discussão teórica. Rosa dos Ventos-Turismo e Hospitalidade, 7(4). https://doi.org/10.18226/21789061.v7iss4p561

Lusch, R. \& Vago, S. (2014). Service-dominant logic: Premises, perspectives, possibilities. Service-dominant logic: Premises, perspectives, possibilities. Cambridge University Press. https://doi.org/10.1017/CB09781139043120

Lutz, C. \& Newlands, G. (2018). Consumer segmentation within the sharing economy: The case of Airbnb. Journal of Business Research, 88, 187-196. https://doi.org/10.1016/j.jbusres.2018.03.019

Martins, G. D. A. \& Theóphilo, C. R. (2009). Metodologia da investigação cientifica. São Paulo: Atlas.

Minkiewicz, J.; Evans, J. \& Bridson, K. (2014). How do consumers co-create their experiences? An exploration in the heritage sector. Journal of Marketing Management, 30(1-2), 30-59. https://doi.org/10.1080/0267257X.2013.800899

Moeller, S.; Ciuchita, R. \& Mahr, D.; Odekerken-Schroder, G.; Fassnacht, M. (2013). Journal of Service Research 16(4), 471-487. https://doi.org/10.1177/1094670513480851

Möhlmann, M. (2015), Collaborative consumption: Determinants of satisfaction and the likelihood of using a sharing economy option again. Journal of Consumer Behaviour, 14(3), 193-207.

https://doi.org/10.1002/cb.1512

Mowen, J. C. \& Minor, M. (1998) Consumer behavior. $5^{\text {a }}$ Ed. Upper Saddle River: Prentice-Hall

Nambisan, S. \& Baron, R. (2009) Virtual customer environments: Testing a model of voluntary participation in value co-creation activities. Journal of Product Innovation Management 26(4), 388 - 406. https://doi.org/10.1111/j.1540-5885.2009.00667.x

O'Cass, A., \& Sok, P. (2015). An exploratory study into managing value creation in tourism service firms: Understanding value creation phases at the intersection of the tourism service firm and their customers. Tourism Management, 51, 186-200. https://doi.org/10.1016/j.tourman.2015.05.024

Ozanne, L.; Ballantine, P. (2010). Sharing as a form of anti-consumption? An examination of toy library users. Journal of Consumer Behaviour, 9(6), 485-498. https://doi.org/10.1002/cb.334

Paik, Y.; Kang, S. \& Seamans, R. (2018) Entrepreneurship, innovation, and political competition: How the public sector helps the sharing economy create value. Strategic Management Journal, 40(4), 503-532. https://doi.org/10.1002/smj.2937

Paul, J., Modi, A., \& Patel, J. (2016). Predicting green product consumption using theory of planned behavior and reasoned action. Journal of retailing and consumer services, 29, 123-134. https://doi.org/10.1016/j.jretconser.2015.11.006

Payne, A. F.; Storbacka, K. \& Frow, P. (2008). Managing the co-creation of value. Journal of the Academy of Marketing Science, 36(1), 83-96. https://doi.org/10.1007/s11747-007-0070-0

Pera, R., Occhiocupo, N., \& Clarke, J. (2016). Motives and resources for value co-creation in a multistakeholder ecosystem: A managerial perspective. Journal of Business Research, 69(10), 4033-4041. https://doi.org/10.1016/j.jbusres.2016.03.047

Pereira, G. A.; Gosling, M. (2019). Alternate title: Push and pull motivations of Brazilian travel lovers. Brazilian Business Review, Vitória, 16(1) https://doi.org/10.15728/bbr.2019.16.1.5

Pine, J.; Gilmore, J. (1998). Welcome to the experience economy, Harvard Business Review, July-August, 97-105. 
Piscicelli, L.; Cooper, T.; Fisher, T. (2015). The role of values in collaborative consumption: insights from a product-service system for lending and borrowing in the UK. Journal of Cleaner Production, 97, 21-29. https://doi.org/10.1016/j.jclepro.2014.07.032

Prahalad, C. \& Ramaswamy, V. (2004a). The future of competition: Co-creating

Prahalad, C. \& Ramaswamy, V. (2004b). Co-creation experiences: The next practice in value co-creation. Tourism Management, 67, 362-375.https://doi.org/10.1002/dir.20015

Prahalad, C. \& Ramaswamy,V. (2000). Co-opting customer competence. Harvard

Prebensen, N. K., \& Xie, J. (2017). Efficacy of co-creation and mastering on perceived value and satisfaction in tourists' consumption. Tourism Management, 60, 166-176. https://doi.org/10.1016/j.tourman.2016.12.001

Pullman, M. \& Gross, R. M. (2003) Welcome to your Experience: where you can chack out anytime you 'd like, but you can never leave. Journal of Business and Management, 9(3), 215-232.

Ranjan, K. R., \& Read, S. (2019). Bringing the individual into the co-creation of value. Journal of Services Marketing. https://doi.org/10.1108/JSM-02-2019-0056

Ribas, J. R., \& Vieira, P. D. C. (2011). Análise multivariada com o uso do SPSS. Rio de Janeiro: Ciência Moderna.

Rifkin, J. (2014). The zero marginal cost society: The internet of things, the collaborative commons, and the eclipse of capitalism. New York: Palgrave Macmillan.

Rihova, I., Buhalis, D., Gouthro, M. B., \& Moital, M. (2018). Social layers of customer-to-customer. Journal of Service Management, 24(5), 553-566. https://doi.org/10.1108/JOSM-04-2013-0092

Rihova, I., Buhalis, D. \& Gouthro, M. B. (2013). Customer-to-customer co-creation practices in tourism: Lessons from Customer-Dominant logic. Tourism Management, 67, 362-375. https://doi.org/10.1016/j.tourman.2018.02.010

Ruvio, A., Shogam, A., (2008). Consumers' need for uniqueness: short-form scale development and crosscultural validation. Int. Mark. Rev. 25 (1), 33-53. https://doi.org/10.1108/02651330810851872

Sastre, P. T. D. N.; Ikeda, A. A. (2012). Reflexões sobre Consumo Colaborativo. Encontro da ANPAD, 36., 2012. Anais[...].Rio de Janeiro: ANPAD.

Stene, A; Holte, H. (2014). A new lease on life: Why do Norwegian Consumers Participate in Collaborative Consumption? A case study of Airbnb and Bilkollektivet. Norwegian School of Economics.

Thomke, S.; Von Hippel, E. (2002). Customers as innovators: A new way to create value. Harvard Business Review, 80(4), 74-81.

Tussyadiah, I. P.; Pesonen, J. (2015). Impacts of peer-to-peer accommodation use on travel patterns. Journal of Travel Research, 1-19. https://doi.org/10.1177/0047287515608505

Van de Glind, P. (2013). The consumer potential of collaborative consumption Amsterdam. Research MSc in Sustainable Development, Utrecht University.

Verleye, K. (2015). The co-creation experience from the Customer Perspective: Its measurement and determinants. Journal of Service Management, 26, 321-342. https://doi.org/10.1108/JOSM-09-2014-0254

Völckner, Franziska (2008). The dual role of price: Decomposing consumers reactions to price. Journal of the Academy of Marketing Science, 36 (3), 359-377. https://doi.org/10.1007/s11747-007-0076-7

Voss, K. E.; Spangenberg, E. R. \& Grohmann, B. (2003). Measuring the hedonic and utilitarian dimensions of consumer attitude. Journal of Marketing Research 40(3) 310-320.

https://doi.org/10.1509/jmkr.40.3.310.19238

Wang, Y. C., Luo, C. C., \& Tai, Y. F. (2017). Implementation of delightful services: From the perspective of frontline service employees. Journal of Hospitality and Tourism Management, 31, 90-104.

https://doi.org/10.1016/j.jhtm.2016.10.006

Westbrook, Robert A. \& William C. Black (1985). A motivation-based shopper typology. Journal ofRetailing, (1), 78-103.

Yadav, R., \& Pathak, G. S. (2016). Young consumers' intention towards buying green products in a developing nation: Extending the theory of planned behavior. Journal of Cleaner Production, 135, 732-739. https://doi.org/10.1016/i.jclepro.2016.06.120 


\section{Informações dos autores}

\section{Gabrielle Maria de Oliveira Chagas}

Doutoranda em Administração com ênfase em Finanças pela Universidade Federal Pernambuco (UFPE). Mestre e Graduada em Administração pela Universidade Federal de Campina Grande (UFCG). Trabalhou como Analista de Finanças da Área Técnica na Fundação Parque Tecnológico da Paraíba.

Contribuições: Concepção da pesquisa, Coleta de Dados, Revisão da literatura, Análise dos dados e Discussão.

E-mail: gabriellemoc52@gmail.com

ORCID: https://orcid.org/0000-0002-7378-9984

\section{Edvan Cruz Aguiar}

Professor Adjunto da Unidade Acadêmica de Administração e Contabilidade da Universidade Federal de Campina Grande (UAAC/UFCG). Bacharel em Administração de Empresas pela Universidade Estadual da Paraíba UEPB. Mestre e Doutor em Administração pela Universidade Federal de Pernambuco PROPAD/UFPE, tendo realizado estágio doutoral na Georgia State University (J. Mack Robinson College of Business). Membro Permanente do Programa de Pós-Graduação em Administração da Universidade Federal de Campina Grande - PPGA/UFC e Líder do Laboratório de Análises e Estudos do Comportamento do Consumidor (L@EC).

Contribuições: Concepção da pesquisa, Revisão da literatura, Análise dos dados e Discussão.

E-mail: edvan.aguiar@ufcg.edu.br

ORCID: https://orcid.org/0000-0002-3433-6210 